\title{
To Improve the Thermal Properties of Mineral Wool by Adding Aerogel
}

\author{
Ming-Wen Hsu, Yi-Shuan Chen, ${ }^{1}$ Yi-Sheng Chen, ${ }^{1}$ \\ Richard Shiey-Shiun Horng, ${ }^{1}$ Chun-Mu Wu, ${ }^{2}$ and Shin-Ku Lee ${ }^{3 *}$ \\ Department of Architecture, National Cheng-Kung University, Tainan 701, Taiwan, R.O.C. \\ ${ }^{1}$ Department of Chemical Engineering, I-Shou University, Kaohsiung 84001, Taiwan, R.O.C. \\ ${ }^{2}$ Department of Mechanical Engineering and Automation Engineering, Kao Yuan University, \\ Kaohsiung 821, Taiwan, R.O.C. \\ ${ }^{3}$ Research Center for Energy Technology and Strategy, National Cheng-Kung University, \\ Tainan 701, Taiwan, R.O.C.
}

(Received August 30, 2016; accepted January 12, 2017)

Keywords: aerogel, mineral wool, thermal conductivity, ambient pressure process

To reduce the cost of fuel and heat loss from pipe surfaces, insulation needs to cover pipes when high temperature fluids are transported through them. Mineral wool has not only low heat conductivity but also good thermal and flame resistant properties. It can be used in a wide range of applications. To improve the performance of thermal insulation, it can be used in a composite material in combination with other insulating materials. Aerogel is regarded as one of the most promising high performance thermal insulation materials today, but only limited commercial products are available thus far due to cost and reliability factors. In this study, aerogel is produced in mineral wool using an ambient pressure drying process. The purpose of this study is to investigate the thermal performance of mineral wool-aerogel composite to meet the requirements for industrial applications. The experimental results indicated that silica aerogel can be successfully produced in mineral wool using an ambient pressure drying process. The cost and production time of this proposed process can be significantly decreased. As aerogel is mixed with mineral wool, the measured thermal conductivity of mineral wool-aerogel composite can be reduced from 0.071 to 0.055 $\mathrm{W} / \mathrm{m} \cdot \mathrm{K}$.

\section{Introduction}

Global warming dramatically effects climate change. Floods, drought, snow storms, and hurricanes happen more commonly and are stronger. Meanwhile, it also causes environmental and social changes, such as rising sea levels and decreased availability of fresh, usable water. Carbon dioxide $\left(\mathrm{CO}_{2}\right)$ is the primary greenhouse gas (GHG) contributing to global warming. Human activities like the use of fuels, coal, and oil have increased the level of global warming by adding $\mathrm{CO}_{2}$ into Earth's atmosphere. Therefore, many conferences, like the 350 carbon emission reduction activity worldwide, and many countries are investing significant resources toward considering how to solve the problems of global warming and climate change. One approach to achieving the goals of energy conservation and $\mathrm{CO}_{2}$ reduction in the industry sector is to use good thermal insulating materials in processing facilities and piping systems.

*Corresponding author: e-mail: sklee1015@gmail.com http://dx.doi.org/10.18494/SAM.2017.1526 
In 1871, the first commercial mineral wool product(1) was made by German scientists, who discovered the specific particle size of raw materials and coke required in the melting furnace to produce a liquid at $1600{ }^{\circ} \mathrm{C}$; the liquid would flow through a lead tank into a centrifugal chamber. The droplets of molten rock exiting the furnace were spun into fiber. In the fiber-forming process, small quantities of binding agents were added to the fibers. The structure and density of the mineral wool product may be adapted according to its final use. These fibers could be made into plates, felt-like or tubular material after which the material would have a very good thermal insulation and acoustic noise reduction performance. Thermal conductivity of mineral wool is $0.045-0.08$ $\mathrm{W} / \mathrm{m} \cdot \mathrm{K}$ at $100{ }^{\circ} \mathrm{C}$, and its density is 40 to $60 \mathrm{~kg} / \mathrm{m}^{3}$. Mineral wool has been used industrially, and it has been shown not only to reduce the noise during transport through pipelines but also to provide excellent thermal insulation for pipelines. Furthermore, mineral wool can be used in various applications as thermal insulation for subsea pipelines, for noise abatement, and as thermal insulation.

In 1930, $\operatorname{Kistler}^{(2)}$ found that aerogels, which display excellent performance as thermal insulation, are perfect thermal insulation for building materials, superior to traditional materials. The aerogel's three-dimensional network structure is mainly composed of silicon dioxide, which accounts for more than $80 \%$ of nanometer-sized holes in the total volume. Aerogels have a low thermal conductivity, high porosity $88-99.8 \%$, low density $20-200 \mathrm{~kg} / \mathrm{m}^{3}$, high surface area 500 $1200 \mathrm{~m}^{2} / \mathrm{g}$, and low refractive index. ${ }^{(3-5)}$ A comparison of physical properties of various materials shown in Table 1 indicates that aerogel has the best thermal insulation and heat resistance.

Due to outstanding properties of aerogels, some aerogel products, such as coatings, blankets, and heat insulation board, have been developed recently. Aerogel heat-insulated blankets formed of silica aerogel possess the lowest thermal conductivity of any known solid and may be reinforced with a non-woven, hydrophobic glass-fiber batting, the thermal conductivity of which is $0.021 \mathrm{~W} /$ $\mathrm{m} \cdot \mathrm{K}$. The process requires mixing with a sol as one would a normal silica aerogel. The sol is poured onto a roll of fibrous batting and heated until gelation; the mat is rolled up and then placed in a reactor while the gel continues to age and strengthen. It is made hydrophobic by additional modifications. After the reaction is complete, the roll is moved into supercritical carbon dioxide for drying. Finally, the roll is heated to evaporate excess solvent and to finish the aerogel insulation blanket.(6) In addition to thermal insulation material, aerogels have been used in thermal superinsulators in solar energy systems, as efficient catalysts and catalytic supports,,$^{(7)}$ and in refrigerators, thermal flasks ${ }^{(8)}$ storage media for organic liquids, ${ }^{(9)}$ and radio luminescent devices. ${ }^{(10)}$

Table 1

Comparison of properties of thermal insulation.

\begin{tabular}{lccccc}
\hline & Mineral wool & Glass fiber & PU foam & Aerogel & honeycomb \\
\hline $\begin{array}{l}\text { Thermal conductivity } \\
(\mathrm{W} / \mathrm{m} \cdot \mathrm{K})\end{array}$ & $0.042-0.07$ & $0.035-0.045$ & $0.022-0.038$ & $0.02-0.04$ & 0.4 \\
\hline Density $\left(\mathrm{kg} / \mathrm{m}^{3}\right)$ & $40-60$ & $30-70$ & $25-35$ & 5 & $30-50$ \\
\hline Advantage & $\begin{array}{c}\text { Cheaper, } \\
\text { nonflammable }\end{array}$ & $\begin{array}{c}\text { Cheaper, } \\
\text { nonflammable }\end{array}$ & $\begin{array}{c}\text { No dust } \\
\text { problem, a good } \\
\text { thermal insulation }\end{array}$ & $\begin{array}{c}\text { The best thermal } \\
\text { insulation and } \\
\text { nonflammable }\end{array}$ & $\begin{array}{c}\text { Sufficient } \\
\text { strength }\end{array}$ \\
\hline Disadvantage & Dust problem & Dust problem & Flammable & Expensive & $\begin{array}{c}\text { Poorest thermal } \\
\text { insulator }\end{array}$ \\
\hline
\end{tabular}


Mineral wool has excellent thermal and flame resistant properties, but mineral wool is thicker than glass fiber wool, because it requires a certain thickness to effectively insulate against heat loss. This becomes inconvenient during construction. Therefore, the purpose of this study was to develop a manufacturing process to add silica aerogel to mineral wool to form a mineral woolaerogel composite. We then also investigated the performance of the mineral wool-aerogel composite.

\section{Experimental Methods}

\subsection{Preparation of mineral wool-aerogel composite}

Two-step mineral wool-aerogel composites were prepared from tetraethyl orthosilicate (TEOS), $\mathrm{H}_{2} \mathrm{O}$, ethyl alcohol $(\mathrm{EtOH})$, hydrogen chloride $(\mathrm{HCl})$, and ammonium hydroxide $\left(\mathrm{NH}_{4} \mathrm{OH}\right)$ at different molar ratios (Table 2) according to the flowchart shown in Fig. 1. The experiment using a two-step process via the ambient drying process ${ }^{(11-13)}$ was low cost and enables easy control of operating conditions. In general, aerogels are usually prepared by supercritical drying of the solvent from a wet gel. ${ }^{(14)}$ The surface tension of the solvent is reduced to zero in the supercritical state in the supercritical drying method. This means the supercritical drying method requires high pressure and is high risk and a relatively expensive process.

The steps in the preparation of a mineral wool-aerogel composite are as follows:

The silica aerogel precursor was TEOS. In the first step, TEOS was diluted with ethanol and deionized water. The molar ratio was kept constant at 1:3:4, and the solution was mixed with acid catalyst $(1 \mathrm{M} \mathrm{HCl})$ at a constant stirring speed at room temperature for the hydrolysis reaction. ${ }^{(15)}$ After the completion of the reaction, silicic acid was obtained. The sol-gel process via catalysis to condensation reaction then yielded the wet gel in a gelation step. The mineral wool was added to the silicic acid, the remaining water and $0.1 \mathrm{M} \mathrm{NH}_{4} \mathrm{OH}$ were mixed in after the sol

Table 2

Synthesis parameters used in silica aerogel sample preparation.

\begin{tabular}{|c|c|c|c|c|c|}
\hline Sample & $\begin{array}{l}\text { TEOS: mineral wool } \\
\text { (weight ratio) }\end{array}$ & $\begin{array}{c}\text { Aerogel } \\
\text { (weight ratio) }\end{array}$ & $\begin{array}{l}\text { Gelation } \\
\text { temperature }\end{array}$ & $\begin{array}{c}\text { Aging } \\
\text { temperature }\end{array}$ & $\begin{array}{c}\text { Drying } \\
\text { temperature }\end{array}$ \\
\hline \multirow{3}{*}{ MA1 } & \multirow{3}{*}{ 1:0.6 } & \multirow{3}{*}{25} & \multirow{3}{*}{$60{ }^{\circ} \mathrm{C}$} & \multirow{3}{*}{$60^{\circ} \mathrm{C}$} & $50^{\circ} \mathrm{C}: 2 \mathrm{~h}$ \\
\hline & & & & & $100^{\circ} \mathrm{C}: 1 \mathrm{~h}$ \\
\hline & & & & & $200^{\circ} \mathrm{C}: 1 \mathrm{~h}$ \\
\hline \multirow{3}{*}{ MA2 } & \multirow{3}{*}{$1: 0.45$} & \multirow{3}{*}{30} & \multirow{3}{*}{$60{ }^{\circ} \mathrm{C}$} & \multirow{3}{*}{$60^{\circ} \mathrm{C}$} & $50^{\circ} \mathrm{C}: 2 \mathrm{~h}$ \\
\hline & & & & & $100^{\circ} \mathrm{C}: 1 \mathrm{~h}$ \\
\hline & & & & & $200^{\circ} \mathrm{C}: 1 \mathrm{~h}$ \\
\hline \multirow{3}{*}{ MA3 } & \multirow{3}{*}{$1: 0.3$} & \multirow{3}{*}{45} & \multirow{3}{*}{$60{ }^{\circ} \mathrm{C}$} & \multirow{3}{*}{$60{ }^{\circ} \mathrm{C}$} & $50^{\circ} \mathrm{C}: 2 \mathrm{~h}$ \\
\hline & & & & & $100^{\circ} \mathrm{C}: 1 \mathrm{~h}$ \\
\hline & & & & & $200^{\circ} \mathrm{C}: 1 \mathrm{~h}$ \\
\hline \multirow{3}{*}{ MA4 } & \multirow{3}{*}{ 1:0.1 } & \multirow{3}{*}{50} & \multirow{3}{*}{$60{ }^{\circ} \mathrm{C}$} & \multirow{3}{*}{$60^{\circ} \mathrm{C}$} & $50^{\circ} \mathrm{C}: 2 \mathrm{~h}$ \\
\hline & & & & & $100^{\circ} \mathrm{C}: 1 \mathrm{~h}$ \\
\hline & & & & & $200^{\circ} \mathrm{C}: 1 \mathrm{~h}$ \\
\hline \multirow{3}{*}{ MA5 } & \multirow{3}{*}{$1: 0.07$} & \multirow{3}{*}{75} & \multirow{3}{*}{$60{ }^{\circ} \mathrm{C}$} & \multirow{3}{*}{$60^{\circ} \mathrm{C}$} & $50^{\circ} \mathrm{C}: 2 \mathrm{~h}$ \\
\hline & & & & & $100^{\circ} \mathrm{C}: 1 \mathrm{~h}$ \\
\hline & & & & & $200^{\circ} \mathrm{C}: 1 \mathrm{~h}$ \\
\hline
\end{tabular}




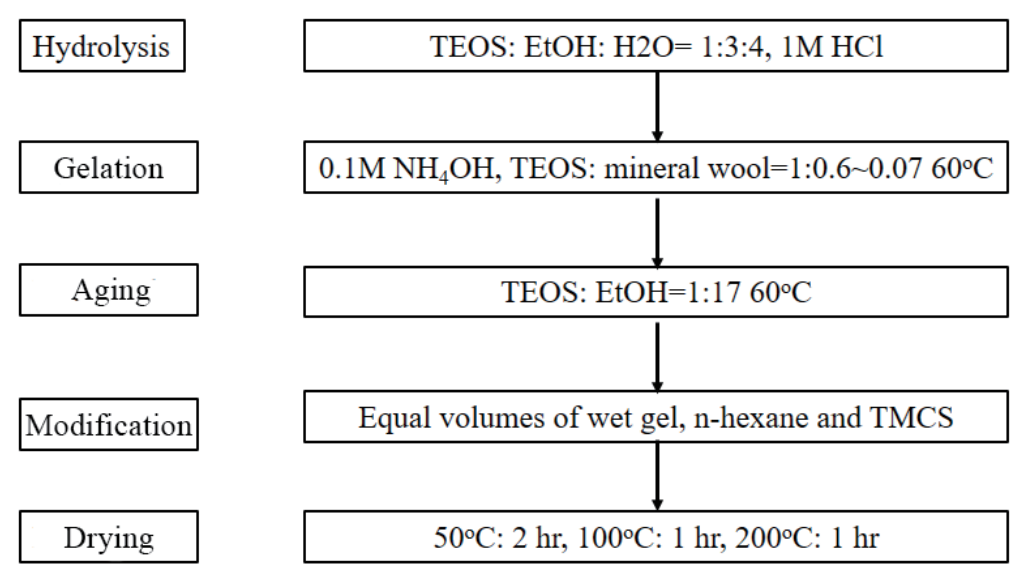

Fig. 1. General scheme for the preparation of mineral wool-aerogel composite samples by the ambient pressure drying method.

was cooled to room temperature. After gelation, a molar ratio TEOS:EtOH $=1: 17$ was used to age the wet gel and to strengthen the gel structure. In this experiment, three solvents [isopropyl alcohol, trimethylchlorosilane (TMCS) and $n$-hexane] were used for the solvent exchange/surface modification. Equal volumes of wet gel, $n$-hexane, and TMCS were added in this step. The $\mathrm{OH}$ group on the wet gel nanopore structure was replaced by TMCS.(16,17) Drying the aerogel is a crucial step. The purpose of drying is to eliminate any inter-gel pore liquid. It is possible that considerable shrinkage may be caused due to capillary stress which deforms or crashes the gel structure during the ambient pressure drying process. ${ }^{(18)}$ To prevent the destruction of the gel structure during the drying process, the gel must be dried under particular conditions. In this study, the gels were dried at $50{ }^{\circ} \mathrm{C}$ for $2 \mathrm{~h}$, and then at $100{ }^{\circ} \mathrm{C}$ for $1 \mathrm{~h}$. To insure complete evaporation of the pore liquid, the gels were finally dried at $200{ }^{\circ} \mathrm{C} 1 \mathrm{~h}$.

\subsection{Characterization of mineral wool-aerogel composite}

The surface area (minimum measurement range: $0.01 \mathrm{~m}^{2} / \mathrm{g}$ ) of the samples was determined by Brunaure-Emmitt-Teller (BET) analysis from the amount of $\mathrm{N}_{2}$ gas adsorbed at various partial pressures $\left(0.01<p / p_{0}<1\right)$ (NOVA $1000 \mathrm{e}$, Quantachrome Instruments, USA). Preheating of samples was carried out under nitrogen flow for $3 \mathrm{~h}$ at $200{ }^{\circ} \mathrm{C}$ to remove all volatile materials. The specific surface areas were determined using the BET equation with an accuracy of $\pm 10 \mathrm{~m}^{2} / \mathrm{g}$. The pore volume (minimum measurement range at STP: $0.0001 \mathrm{cc} / \mathrm{g}$ ) and pore size distributions (measurement range: 3.5-4000 $\AA$ ) were measured using the Barrett-Joyner-Halenda (BJH) cumulative pore volume method. Fourier transform infrared spectroscopy (FTIR, Thermo iS50, USA) with $4 \mathrm{~cm}^{-1}$ resolution and 40 scans for each curve was employed to investigate the chemical bonding state of the modified mineral wool-aerogel composites. A thermal conductivity analyzer (TCI-3-A; TCi, measurement range: $0.025-30 \mathrm{~W} / \mathrm{m} \cdot \mathrm{K}$, error less than $1 \%$ ) was used to measure the thermal conductivity of the mineral wool-aerogel composites. 


\section{Results and Discussion}

\subsection{BET analysis}

Figure 2 shows the nitrogen adsorption-desorption isotherms of mineral wool-aerogel composite samples prepared under different conditions. For the samples synthesized at high mineral-wool/ TEOS ratio (samples MA1 and MA2 or MA3), a type-IV adsorption isotherm according to IUPAC classification ${ }^{(18)}$ is observed, indicating the presence of micropores. All other samples (samples MA4 and MA5) exhibit type-V adsorption isotherms, which indicates the presence of mesopores. Table 3 shows the pore volume, surface area, average pore diameter, bulk density, and porosity of mineral wool-aerogel composites according to the results of nitrogen adsorption measurements. This measurement is based on the nitrogen adsorption properties of a solid surface at a specific pressure, the sample particles' surfaces at extremely low temperatures of the gas molecules with reversible physical adsorption, and the value of the adsorption equilibrium corresponding to the

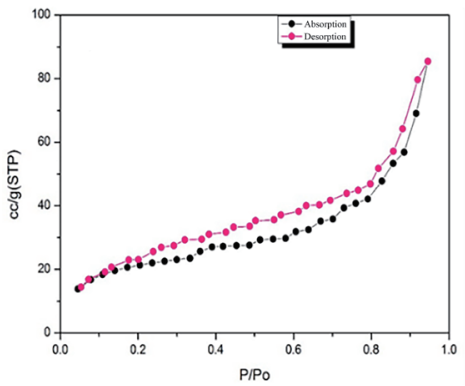

(a)

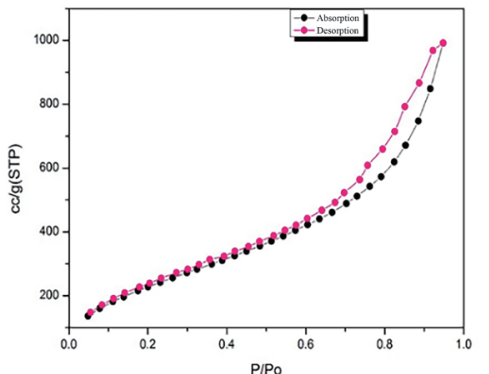

(d)

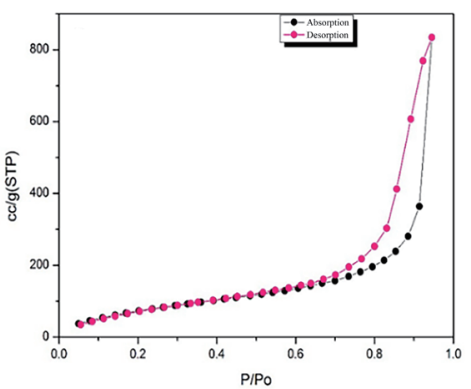

(b)

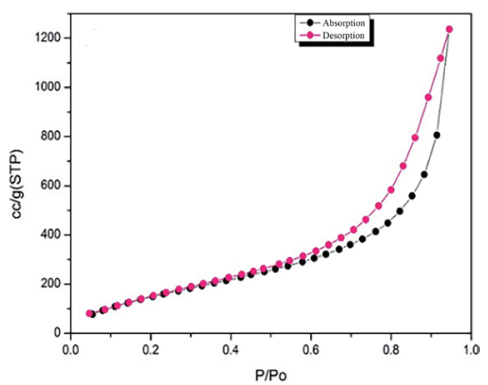

(c)

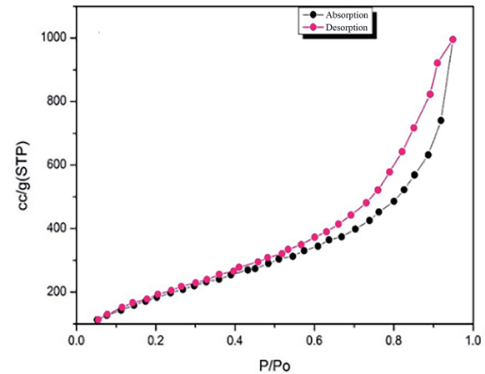

(e)

Fig. 2. (Color online) Nitrogen adsorption-desorption isotherms of mineral wool-aerogel composites: (a) MA1, (b) MA2, (c) MA3, (d) MA4, and (e) MA5.

Table 3

Physical properties of mineral wool-aerogel composites.

\begin{tabular}{lcccccc}
\hline Sample & $\begin{array}{c}\text { Surface area } \\
\left(\mathrm{m}^{2} / \mathrm{g}\right)\end{array}$ & $\begin{array}{c}\text { Pore volume } \\
\left(\mathrm{cm}^{3} / \mathrm{g}\right)\end{array}$ & $\begin{array}{c}\text { Porosity } \\
(\%)\end{array}$ & $\begin{array}{c}\text { Average pore } \\
\text { diameter }(\mathrm{nm})\end{array}$ & $\begin{array}{c}\text { Bulk density } \\
\left(\mathrm{g} / \mathrm{cm}^{3}\right)\end{array}$ & $\begin{array}{c}\text { Average particle } \\
\text { size }(\mathrm{nm})\end{array}$ \\
\hline MA1 & 102 & 0.8 & 63 & 0.2 & 0.814 & 26 \\
MA2 & 295 & 1.08 & 70 & 1.2 & 0.66 & 9 \\
MA3 & 423 & 1.2 & 72 & 1.8 & 0.616 & 6 \\
MA4 & 537 & 2.12 & 82 & 2.2 & 0.396 & 5 \\
MA5 & 779 & 3.08 & 87 & 3.1 & 0.286 & 3.5 \\
\hline
\end{tabular}


given pressure. By measuring the magnitude of the adsorption equilibrium at that surface area, the average pore size and pore volume of the sample could be determined. In addition, the porosity, bulk density, and average particle size were calculated using Eqs. (1)-(3), respectively:(19-21)

$$
\begin{gathered}
P=\frac{v}{v+\frac{1}{\rho_{s}}} \\
\rho_{b}=\rho_{s}(1-P) \\
d=\frac{6}{S+\rho_{s}}
\end{gathered}
$$

where $P$ is the porosity, $v$ is the total pore volume, $\rho_{b}$ is the bulk density, $d$ is the average particles size, $S$ is the specific surface area, and $\rho_{s}$ is the particle density, which is $2.2 \mathrm{~cm}^{3} / \mathrm{g}$ for amorphous silica. The average pore size was calculated from the BET surface area.

All samples of mineral wool-aerogel composites exhibited specific surface areas in the range of $100-800 \mathrm{~m}^{2} / \mathrm{g}$. The average particle size and pore diameter are in the range of $26-3.5 \mathrm{~nm}$ and $0.2-3.1$ $\mathrm{nm}$, respectively. The MA1 sample with a mineral-wool/TEOS weight ratio of 0.6 shows a smaller pore size of $0.2 \mathrm{~nm}$ and an average particle size of $26 \mathrm{~nm}$ with a wide pore-size distribution, while sample MA5 with a mineral-wool/TEOS weight ratio of 0.07 shows pore size of $3.1 \mathrm{~nm}$ and an average particle size of $3.5 \mathrm{~nm}$ with a narrow pore size distribution. It is more evident from Table 3 that the particle size decreases from 26 to $3.5 \mathrm{~nm}$, the pore size increases from 0.2 to $3.1 \mathrm{~nm}$, and the surface area increases from 102 to $779 \mathrm{~m}^{2} / \mathrm{g}$ as the mineral-wool/TEOS weight ratio decreases from 0.6 in MA1 to 0.07 in MA5 sample. This result indicates that a decrease in the mineral-wool/ TEOS weight ratio enlarges the pores. The MA5 sample with large average pore sizes exhibited high specific surface areas compared to other samples having relatively smaller average pore sizes. It can be clearly observed that the more aerogel content within a synthetic mineral wool-aerogel composite, the higher the overall surface area.

\subsection{FTIR analysis}

FTIR spectra of mineral wool-aerogel composite samples synthesized at different mineralwool/TEOS weight ratios with surface modification using TMCS are shown in Fig. 3. The wetting behavior of the hydrophobic surfaces is governed mainly by the chemical composition of surface. The absorption peaks near $1100 \mathrm{~cm}^{-1}$ are due to $\mathrm{Si}-\mathrm{O}-\mathrm{Si}$ asymmetric stretching vibrations, indicating successful chemical gelation by covalent bonding among TEOS molecules. The absorption peaks around $1750-1800 \mathrm{~cm}^{-1}$ corresponding to $\mathrm{S}-\mathrm{CH}_{3}$ terminal groups are visible and confirm the surface modification of the wet gel within mineral wool by TMCS during silylation. The absorption peaks around $3100-3700 \mathrm{~cm}^{-1}$ corresponding to the $\mathrm{OH}$ group indicate that mineral wool does not react with TMCS. Thus, $\mathrm{OH}$ groups still exist on the surface of mineral wool, but not within the aerogels. As shown in Fig. 3, when the mineral-wool/TEOS weight ratio decreases, the $1650 \mathrm{~cm}^{-1}$ peak gradually disappears, indicating that the $\mathrm{Si}-\mathrm{CH}_{3}$ group is oxidized. On the other hand, when the mineral-wool/TEOS weight ratio is lower than 0.1 , the peaks near 2850-3000 $\mathrm{cm}^{-1}$ gradually appear, showing that when more $\mathrm{SiO}_{2}$ aerogel is synthesized, $\mathrm{Si}-\mathrm{OH}$ groups are produced. This analysis can determine the identity of the chemical bonds in the mineral woolaerogel composites. 


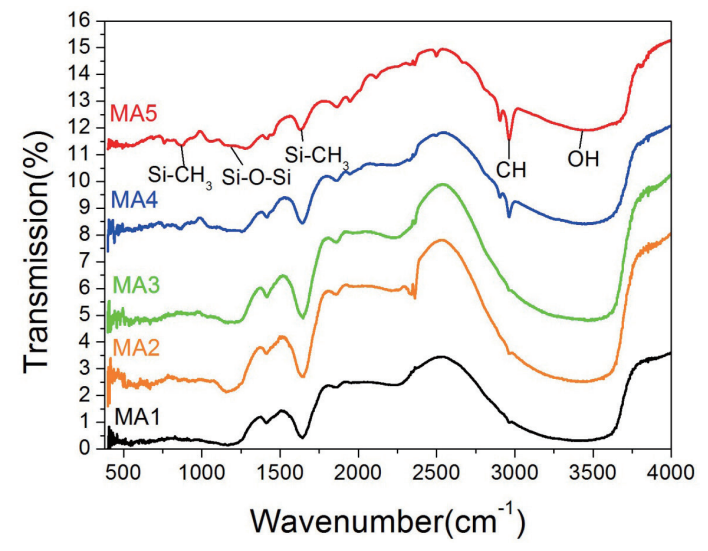

Fig. 3. (Color online) FTIR spectra of mineral wool-aerogel composites.

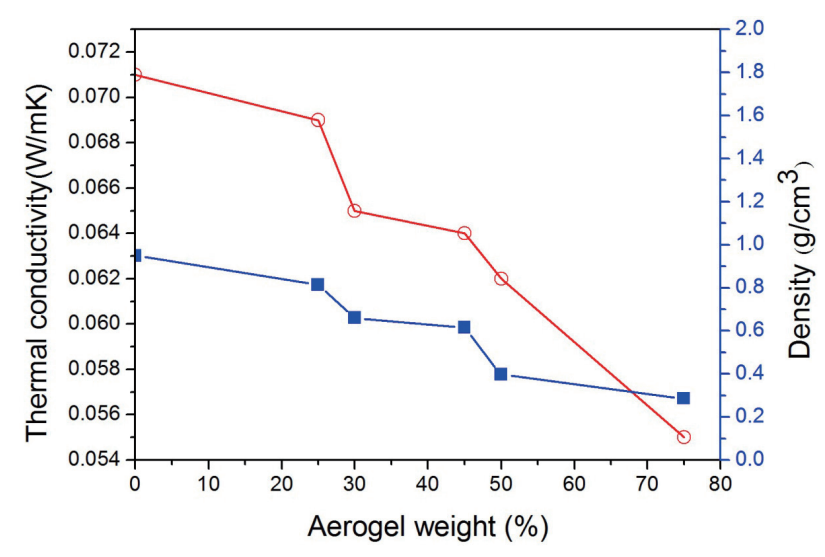

Fig. 4. (Color online) Thermal conductivity and density vs aerogel weight fraction.

\subsection{Thermal conductivity analysis}

Thermal conductivity is an important indicator for evaluating the thermal performance of a material under constant conditions. The thermal conductivities of pure aerogel powder synthesized in this study and the mineral wool blanket are 0.040 and $0.071 \mathrm{~W} / \mathrm{m} \cdot \mathrm{K}$, respectively. Figure 4 shows the thermal conductivity and density of the mineral wool-aerogel composites as a function of aerogel weight fraction. As the aerogel weight volume fraction increased, thermal conductivity significantly decreased. This could be explained by the fact that heat transfer may occur primarily through aerogel particles. The mechanisms of heat transfer in mineral wool-aerogel composite are dominated by thermal conduction via mineral wool, lattice vibrations, and heat conducted by radiations via aerogel. Based on the proposed manufacturing process, the homogeneous mineral wool-aerogel composite containing $75 \mathrm{wt} \%$ of aerogel particles could be obtained, and it had very low thermal conductivity $(0.055 \mathrm{~W} / \mathrm{m} \cdot \mathrm{K})$ similar to that $(0.040 \mathrm{~W} / \mathrm{m} \cdot \mathrm{K})$ of pure aerogel.

\section{Conclusions}

In this study, mineral wool-aerogel composites were prepared at ambient temperature and pressure drying method using TMCS as a surface modification agent. Nitrogen adsorption analysis was used to determine the specific surface area and pore size distribution of samples prepared by the BET and BJH techniques, respectively. FTIR spectroscopy was employed to investigate the chemical bonding within the composites. Finally, the thermal conductivity of composites was measured to evaluate their thermal performance, which is excellent to thermal insulation materials. Specific conclusions are as follows:

1. The experimental process required about twelve hours. The time can be effectively shortend to enable high volume manufacturing in industry.

2. Thermal conductivity analysis shows which mineral wool-aerogel has the best thermal resistance properties with a thermal conductivity coefficient $0.055 \mathrm{~W} / \mathrm{m} \cdot \mathrm{K}$. Other samples contain too little aerogel, so their thermal resistance properties do not show significant improvement. 
3. The FTIR analysis sample MA5 may be compared to that of other samples. The intensities of the absorption bands due to silicon groups are stronger than in other samples, which indicates that TMCS reacted with mineral wool-aerogel composites. Its characteristics are superior to other samples.

4. BET analysis showed that mineral wool-aerogel composites have a nano-porous structure, and for MA5 the surface area $\left(779 \mathrm{~m}^{2} / \mathrm{g}\right)$, pore volume $\left(3.08 \mathrm{~cm}^{3} / \mathrm{g}\right)$, porosity $(87 \%)$, and low bulk density indicate that the pore structure is uniformly dense.

5. Aerogel can effectively reduce the thermal conductivity of mineral wool insulation to increase its effectiveness ; the composite has properties of both materials.

\section{Acknowledgements}

The gratitude of the authors is expressed to the Ministry of Science and Technology of Taiwan for their financial support of this study under projects MOST 104-3113-E-006-019-CC2.

\section{References}

1 Wikipedia: http://en.wikipedia. org/wiki/Mineral_wool (accessed 15 December 2013).

2 S. S. Kistler: Nature 127 (1931) 741.

3 F. Shi, L. Wang, and J. Liu: Mater. Lett. 60 (2006) 3718.

4 A. V. Rao, E. Nilsen, and M.A. Einarsrud: J. Non-Cryst. Solids 296 (2001) 165.

5 H.X. Zhang, X. D. He, and F. He: J. Alloys Compd. 469 (2009) 366.

6 C. J. Stepanian, G. Gould, and R. Begah: US patent, US7078359 B2, Aspen aerogel, lnc, 2006.

7 G. M. Pajonk: Appl. Catal. 72 (1991) 217.

8 A. V. Rao and R. R. Kalesh: SCI Technol. Adv. Mater. 4 (2003) 509.

9 S. Yun, H. Luo, and Y. Gao: RSC Adv. 4 (2014) 4535.

10 S. T. Reed, C. S. Ashley, C. J. Brinker, R. J. Walko, R. Ellefsoon, and J. Gill: SPIE 1328 (1990) 220.

11 S. M. Kim, K. Chakrabarti, E. O. Oh, and C. M. Wang: J. Sol-Gel. Sci. Technol. 27 (2003) 149.

12 P. Wawzzynail, G. Rogacki, J. Pruba, and Z. Bartzak: J. Non-Cryst. Solids 285 (2001) 50.

13 M. L. Liu, D. A. Yang, and Y. F. Qu: J. Non-Cryst. Solids 354 (2008) 4927.

14 P. H. Tewari, A. J. Hunt, and K. D. Lofftus: Mater. Lett. 3 (1985) 363.

15 G. A. Nicolaon and S. J. Teichner: Bull. Soc. Chim. Fr. 5 (1968) 1900.

16 H. R. Kricheldorf: Silicon in Polymer Synthesis (Springer-Verlag, Berlin, 1996).

17 S. D. Bhagat, C. S. Oh, Y. H. Kim, Y. S. Ahn, and J. G. Yeo: Microporous Mesoporous Mater. 100 (2007) 350.

18 J. Rouquerol, D. Avnir, C. W. Fairbridge, D. H. Everett, J. M. Haynes, N. Pernicone, J. D. F. Ramsay, K. S. W. Sing, and K. K. Unger: Pure Appl. Chem. 66 (1994) 1739.

19 L. Zhang, J. Gu, H. Yao, and Y. Zhang: Rare Met. 30 (2011) 552.

20 A. Soleimani Dorcheh and M. H. Abbasi: J. Mater. Process. Technol. 199 (2008) 10.

21 N. Leventis: Acc. Chem. Res. 40 (2007) 874. 